University of Nebraska - Lincoln

DigitalCommons@University of Nebraska - Lincoln

Preperitoneal insufflation pressure of the abdominal wall in a porcine model

Riley E. Reynolds

Benjamin Wankum

Sean J. Crimmins

Mark A. Carlson

Benjamin S. Terry

Follow this and additional works at: https://digitalcommons.unl.edu/mechengfacpub

Part of the Mechanics of Materials Commons, Nanoscience and Nanotechnology Commons, Other Engineering Science and Materials Commons, and the Other Mechanical Engineering Commons

This Article is brought to you for free and open access by the Mechanical \& Materials Engineering, Department of at DigitalCommons@University of Nebraska - Lincoln. It has been accepted for inclusion in Mechanical \& Materials Engineering Faculty Publications by an authorized administrator of DigitalCommons@University of Nebraska Lincoln. 


\title{
Preperitoneal insufflation pressure of the abdominal wall in a porcine model
}

\author{
Riley E. Reynolds, ${ }^{1}$ Benjamin P. Wankum, ${ }^{1}$ Sean J. \\ Crimmins, ${ }^{1}$ Mark A. Carlson, ${ }^{2}$ and Benjamin S. Terry ${ }^{1}$ \\ 1 Department of Mechanical Engineering, University of Nebraska-Lincoln, \\ Lincoln, NE 68588, USA \\ 2 Department of Surgery, University of Nebraska Medical Center, Omaha, NE \\ 68198, USA \\ Riley E. Reynolds and Benjamin P. Wankum have contributed equally as primary \\ authors. \\ Corresponding author — Benjamin P. Wankum, email bwankum2@unl.edu
}

\begin{abstract}
Background Most complications and adverse events during laparoscopic surgery occur during initial entry into the peritoneal cavity. Among them, preperitoneal insufflation occurs when the insufflation needle is incorrectly placed, and the abdominal wall is insufflated. The objective of this study was to find a range for static pressure which is low enough to allow placement of a Veress needle into the peritoneal space without causing preperitoneal insufflation, yet high enough to separate abdominal viscera from the parietal peritoneum.

Methods A pressure test was performed on twelve fresh porcine carcasses to determine the minimum preperitoneal insufflation pressure and the minimum initial peritoneal cavity insufflation pressure. Each porcine model had five needle placement categories. One category tested the initial peritoneal cavity insufflation pressure beneath the umbilicus. The four remaining categories tested the preperitoneal insufflation pressure at four different anatomical locations on the abdomen that can be used for initial entry. The minimum initial insufflation pressures from each
\end{abstract}

Published in Surgical Endoscopy and Other Interventional Techniques 2021

doi:10.1007/s00464-020-08275-z

Submitted 14 August 2020; accepted 24 December 2020.

Copyright (C) 2021 the authors, under exclusive license to Springer Science+Business Media, LLC part of Springer Nature. Used by permission. 
carcass were then compared to the preperitoneal insufflation pressures to obtain an optimal range for initial insufflation.

Results Increasing the insufflation pressure increased the probability of preperitoneal insufflation. Also, there was a statistically significant difference $(p<0.05)$ between the initial peritoneal cavity insufflation pressures $(8.83 \pm 4.19 \mathrm{mmHg})$ and the lowest preperitoneal pressures $(32.54 \pm 7.84 \mathrm{mmHg}$ ) (mean $\pm \mathrm{SD}$ ).

Conclusion Pressures greater than $10 \mathrm{mmHg}$ resulted in initial cavity insufflation and pressures greater than $20 \mathrm{mmHg}$ resulted in preperitoneal insufflation in porcine models. By knowing the minimum pressure required to separate the layers of the abdominal wall, the risk of preperitoneal insufflation can be mitigated while obtaining safe and efficient entry into the peritoneal cavity. The findings in this research are not a guideline for trocar or Veress needle placement, but instead reveal preliminary data which may lead to more studies, technology, etc.

Keywords Laparoscopic surgery, Preperitoneal insufflation, Pressure profile test, Pneumoperitoneum, Veress needle, Insufflation

Laparoscopic surgery is a minimally invasive technique that utilizes percutaneous access to the peritoneal space, which under physiological conditions is only a potential space [1]. Although the standard techniques to access the peritoneal space are relatively safe, most adverse events associated with this access occur during initial entry [1-3]. These events include visceral perforation [4], preperitoneal (abdominal wall) insufflation [5], gas embolism [6], abdominal hematoma [7], and failure to gain peritoneal access [8]. Research and development of technologies to increase the safety and efficacy of peritoneal access during laparoscopic surgery have been ongoing for decades, but incidents of injury have remained constant over the past 25 years [9].

There are various techniques for accessing the peritoneal cavity but the closed entry method is one of the more common methods [3]. One variation of the closed method involves the Veress insufflation needle where a small (several millimeters) skin incision is made, through which the needle is inserted into the peritoneal cavity [10]. Safety checks to confirm the placement of the needle within the peritoneal cavity include Palmer's test, the pressure profile test, the double-click acoustic test, and the hanging saline drop test [11-13]. The pressure profile test is the most sensitive and reliable, but all of these safety checks have drawbacks in confirming successful entry [11-13].

After peritoneal access has been obtained, carbon dioxide gas flow through the needle is initiated and the peritoneal cavity is insufflated (this technique is known as subsequent insufflation) [14]. Gas 
insufflation of the peritoneal cavity creates a working space in which an operation can be performed [15]. Alternatively, concomitant insufflation can be performed, in which the insufflation needle is inserted through the skin incision and into the peritoneal cavity while carbon dioxide flows through the needle [14]. If concomitant insufflation is paired with the pressure profile test, then a pressure drop indicates that the Veress needle has breached the parietal peritoneum and has accessed the potential space of the peritoneal cavity [16]. A drawback to both subsequent and concomitant insufflation is preperitoneal insufflation, which can cause subcutaneous emphysema and access failure [17].

Several different studies have found that the pressure to create peritoneal cavity initial insufflation is less than $10 \mathrm{mmHg}[3,11,12]$, but the insufflation pressure of the abdominal wall has yet to be determined. The goal of this study was to find an optimal range $\left(P_{\text {opt }}\right)$ of static pressures which would be low enough to facilitate placement of a Veress needle into the peritoneal space without causing preperitoneal insufflation $\left(P_{p p i}\right)$ (Fig. 1), yet high enough to separate abdominal viscera (such as the small intestine) from the parietal peritoneum $\left(P_{p c}\right)$ as described by the inequality:

$$
P_{p c}<P_{o p t}<P_{p p i}
$$

where $P_{p c}$ is the initial pressure to insufflate the peritoneal cavity, $P_{o p t}$ is the optimal pressure range, and $P_{p p i}$ is the preperitoneal insufflation pressure.

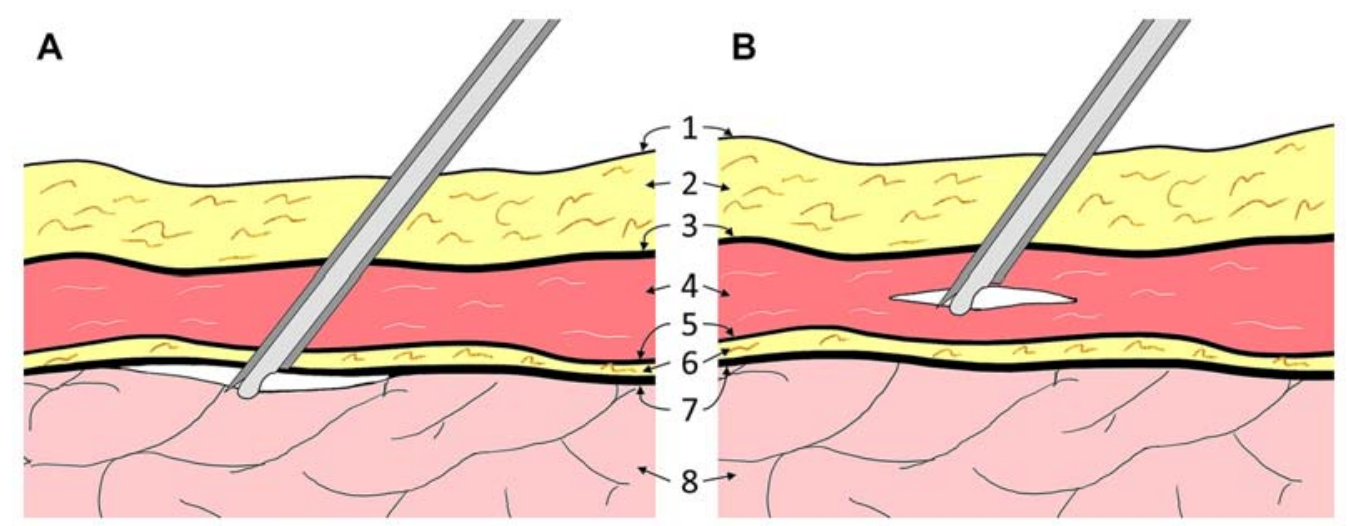

Fig. 1 Visualization of preperitoneal insufflation within the rectus abdominis muscle (A) and initial separation of the abdominal organs from the parietal peritoneum (B). Layers of the abdominal wall depicted are 1. Skin, 2. Subcutaneous fat, 3. Anterior rectus sheath, 4 . Rectus abdominis muscle, 5. Posterior rectus sheath, 6 . Preperitoneal fat, 7. Parietal peritoneum, and 8 . Abdominal viscera. 
By knowing the minimum pressure required to separate the layers of the abdominal wall, one should be able to minimize the risk of preperitoneal insufflation while obtaining safe and efficient entry into the peritoneal cavity. To find the minimum preperitoneal insufflation pressure, a Veress needle was inserted into a porcine abdomen at varying pressures and various locations, and any events of preperitoneal insufflation were recorded.

\section{Methods}

The experiments reported herein were conducted according to the principles set forth in the National Institute of Health Publication No. 80-23, Guide for the Care and Use of Laboratory Animals and the Animal Welfare Act of 1966, as amended [18].The animal protocol pertaining to this manuscript was approved by the Institutional Animal Care and Use Committee (IACUC) at the University of Nebraska- Lincoln (ID \#1909). All procedures were performed in animal facilities approved by the Association for Assessment and Accreditation of Laboratory Animal Care International (AAALAC) and by the Office of Laboratory Animal Welfare of the Public Health Service $[19,20]$. The Duroc and Duroc Landrace cross pigs that were used for the study were purchased from the Plymouth Ag Group, Beatrice, NE [21].

A power analysis with an estimated difference in means of $10 \mathrm{mmHg}$ and a power of 0.8 was used to determine that five animals were necessary for the study. Although only five pigs were needed, twelve pigs were available from other animal studies. Thus, the study was performed on 12 female pigs (two Duroc and ten Duroc Landrace cross). The two Duroc and three of the Duroc Landrace cross-bread pig's weights ranged from 45 to $50 \mathrm{~kg}(47.2 \pm 2.05)$, while the remaining seven Duroc Landrace cross-bread weights ranged from 72 to $76 \mathrm{~kg}(74.2 \pm 1.46)$. Pigs were selected to model the human abdominal wall because of their duallayer fascia, analogous underlying anatomy, and similar tissue mechanical properties [22]. The animals were used for other research purposes, but none of the previous work affected the abdominal wall or the peritoneal cavity. The experiments were completed on non-living subjects, within 2 h of euthanasia. 


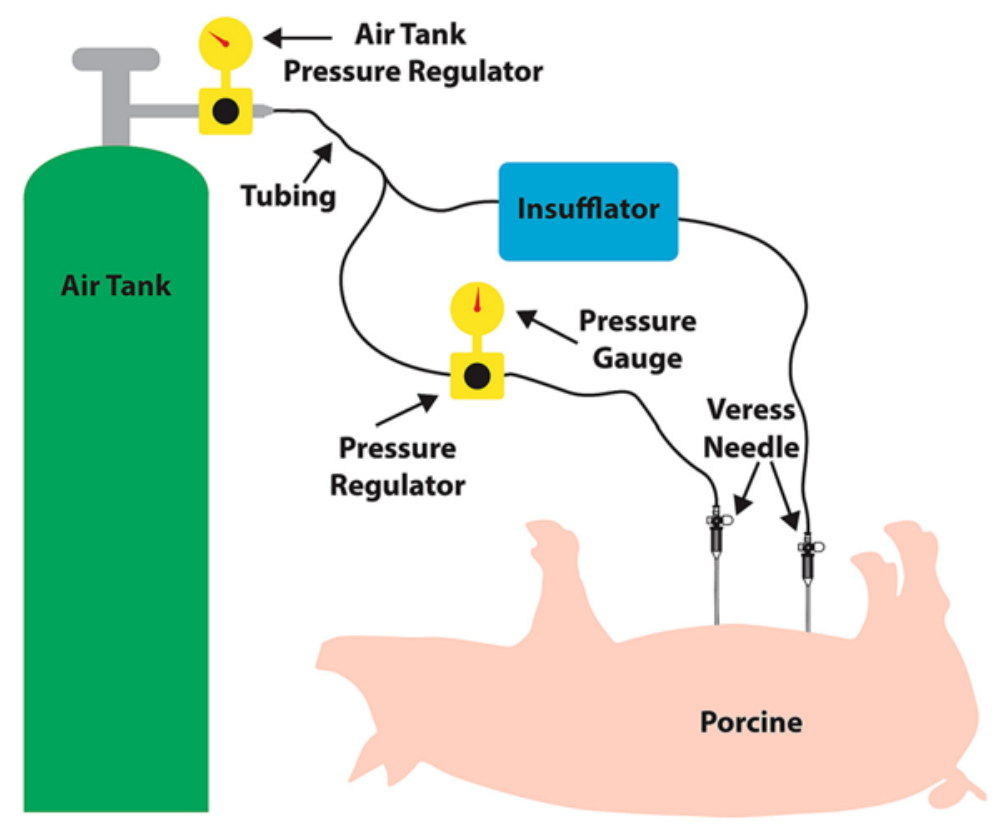

Fig. 2 Experimental setup for determining the optimal initial insufflation pressure range. The Veress needle attached to the insufflator was used to maintain pneumoperitoneum at $10 \mathrm{mmHg}$, while the other Veress needle was used for preperitoneal insufflation testing.

The experimental setup is shown in Fig. 2. An air tank was used to provide pressure for the tests. The initial air pressure was controlled with a pressure regulator attached to the air tank and was set to around 100 psi. An insufflator (Laparoflator 26012, Karl Storz, Germany) and a pressure regulator (1888K1, McMaster-Carr, USA) with a calibrated pressure gage attached (4269K1, McMaster-Carr, USA) were connected in parallel to the air supply. The insufflator was connected to a disposable Veress needle (PN150, Ethicon Endo-Surgery, Guaynabo, Puerto Rico) and was used to control pneumoperitoneum. A second Veress needle connected to the pressure regulator was used to control the concomitant insufflation pressure. After making $5 \mathrm{~mm}$ skin incisions [3], all needles were inserted slowly and incrementally at a $90^{\circ}$ angle relative to the abdomen at their test location (Fig. 3).

Five needle placement categories resembling anatomical locations were identified for peritoneal cavity access (Fig. 3, Table 1). The X category had one test location, just below the umbilicus, and is a common entry location during a laparoscopic procedure [23]. The M category was 


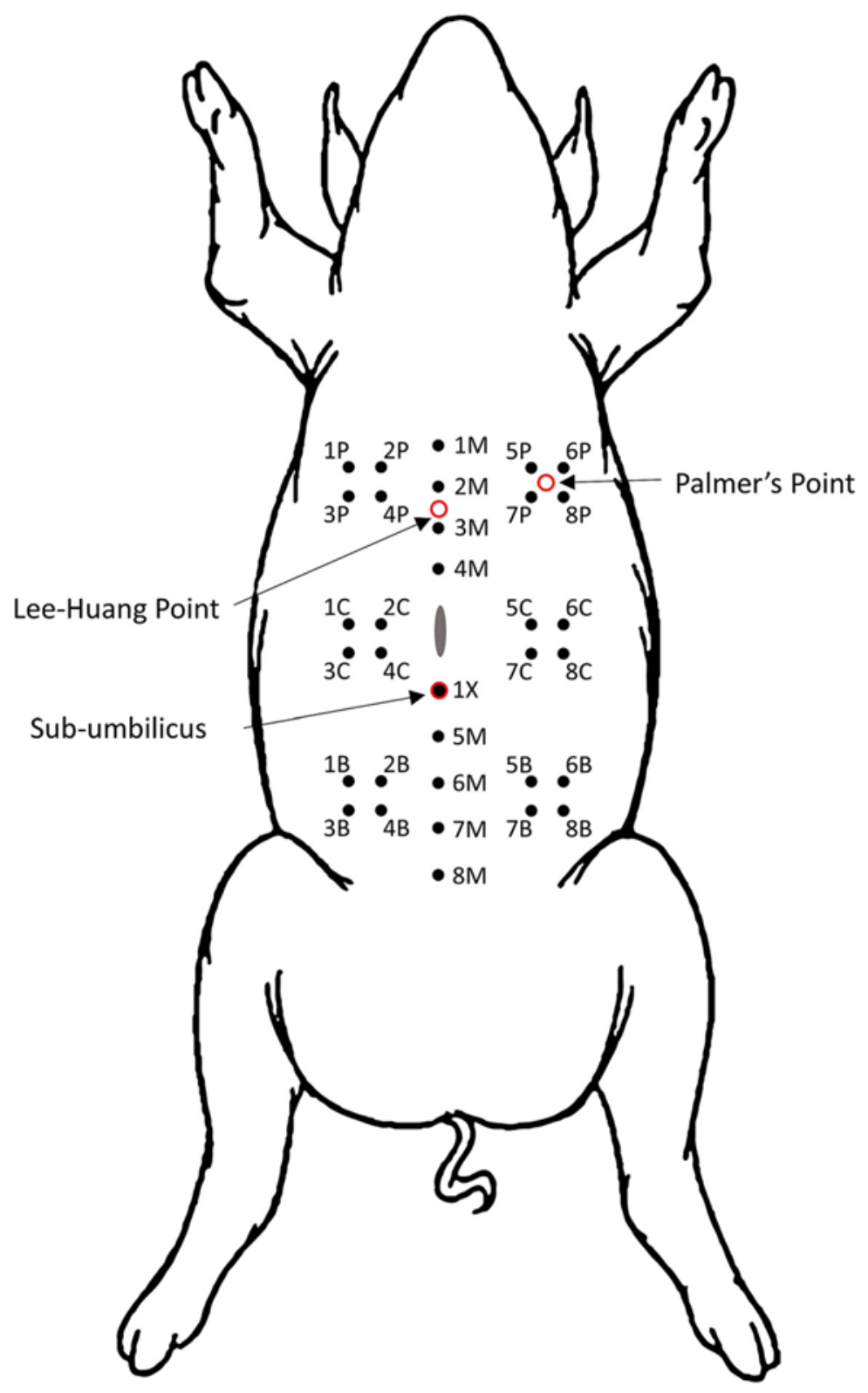

Fig. 3 Needle locations for the five placement categories $X, M, P, C$, and $B$.

along the abdominal midline. The Veress needle is frequently placed by physicians beneath the umbilicus or sometimes at the Lee-Huang point [24]. The Lee-Huang point is located midway between the xiphoid process and the umbilicus along the midline [24]. It typically is used when 
Table 1 Needle placement category locations and their respective representation of common peritoneal cavity access points.

\begin{tabular}{lllr} 
Category & Anatomical location & Category representation & $\begin{array}{c}\text { \# of Needle } \\
\text { placements }\end{array}$ \\
\hline X & Sub-umbilicus & Sub-umbilicus & 1 \\
M & Median plane & Sub-umbilicus, Lee-Huang & 8 \\
P & Right and left upper quadrants & Palmer's point & 8 \\
C & Transumbilical plane & Subsequent trocar placement & 8 \\
B & Right and left lower quadrants & Subsequent trocar placement & 8 \\
& & Total & 33 \\
\hline
\end{tabular}

The $\mathrm{X}$ category placement tested the initial insufflation pressure. All other categories tested the preperitoneal insufflation pressure.

previous operations preclude the sub-umbilical incision or after failed access attempts below the umbilicus [25]. The remaining three placement categories (P, C, and B) assumed that the abdominal wall was relatively symmetrical about the abdominal midline. The $\mathrm{P}$ category was located near Palmer's point which is $3 \mathrm{~cm}$ below the left subcostal border in the midclavicular line [24]. It may be used as another alternative to the sub-umbilical placement for patients who are known or suspected to have periumbilical adhesions or have failed attempts at the umbilicus [26]. It also may be considered for both obese and very thin patients [3]. The $\mathrm{C}$ and $\mathrm{B}$ categories are not typically used for initial access in laparoscopic operations but can be used for subsequent trocar insertion [23, 27].

The first needle was placed at location $1 \mathrm{X}$, and insertion into the peritoneal cavity was indicated by the doubleclick test [24]. After the needle was placed, the static pressure was increased at intervals of $2.6 \mathrm{mmHg}$ (based on the resolution of the pressure gage) starting at $0 \mathrm{mmHg}$. Once airflow occurred, indicating separation of the visceral and parietal peritonea, the pressure was recorded as the initial insufflation pressure. This could only be tested once per animal because, according to pilot studies, the pressure to subsequently insufflate the peritoneal cavity decreased after the initial separation of the viscera from the abdominal wall. Pneumoperitoneum was then established with an insufflator and maintained at a cavity pressure of $10 \mathrm{mmHg}$. While the only initial indication of correct needle placement was the double-click test, it was confirmed when insufflation occurred, and pneumoperitoneum was established. 
The initial Veress needle at $1 \mathrm{X}$ remained inside the peritoneal cavity for the remainder of the experiment to maintain pneumoperitoneum. A second Veress needle was inserted with concomitant air insufflation to determine the separation pressure of the abdominal wall. Pneumoperitoneum was sustained for the remaining needle tests because the lack of resistance on the entering needle (from the separated abdominal wall and underlying viscera) indicated to the user when the needle tip had breached the parietal peritoneum. The second needle was inserted at several different locations. One site from each of the remaining test categories $(\mathrm{M}, \mathrm{B}, \mathrm{P}, \mathrm{C})$ was randomly selected for each pressure beginning at $5.2 \mathrm{mmHg}$ and ranging up to $41.4 \mathrm{mmHg}$ at intervals of $5.2 \mathrm{mmHg}$. The needle was placed slowly and incrementally. At each increment, the downward force on the Veress needle was momentarily released to allow airflow detection. Airflow was confirmed by the pressure drop that occurred as the pressure changed from static to dynamic pressure. If insufflation occurred before breaching the peritoneum, the test site and pressure were recorded as a failure to access the peritoneal cavity. If the needle made it into the peritoneal cavity without causing preperitoneal insufflation, then the test site and pressure were recorded as a success.

\section{Results}

Figure 4 shows the distribution of the preperitoneal insufflation occurrences for the M, P, C, and B categories at each pressure interval. As seen in the figure, category $M$ had two instances with uncharacteristically lower insufflation pressures of 15.5 and $20.7 \mathrm{mmHg}$ on two different pigs. These tests were both performed at location $8 \mathrm{M}$ (Fig. 3) which may be too low on the abdominal wall. Thus, the assumption that the linea alba has consistent anatomy from 1 to $8 \mathrm{M}$ may be invalid on some pigs. That said, the difference in the number of preperitoneal insufflations between the left and right sides was statistically insignificant $(p>$ $0.05)$, indicating the assumption of anatomical symmetry between the left and right sides of the pig was justified.

The lowest pressures to insufflate the abdominal wall per category per pig (excluding the anomalies in the M category) were taken to compare to the peritoneal cavity initial insufflation pressure (category $\mathrm{X}$ ) 


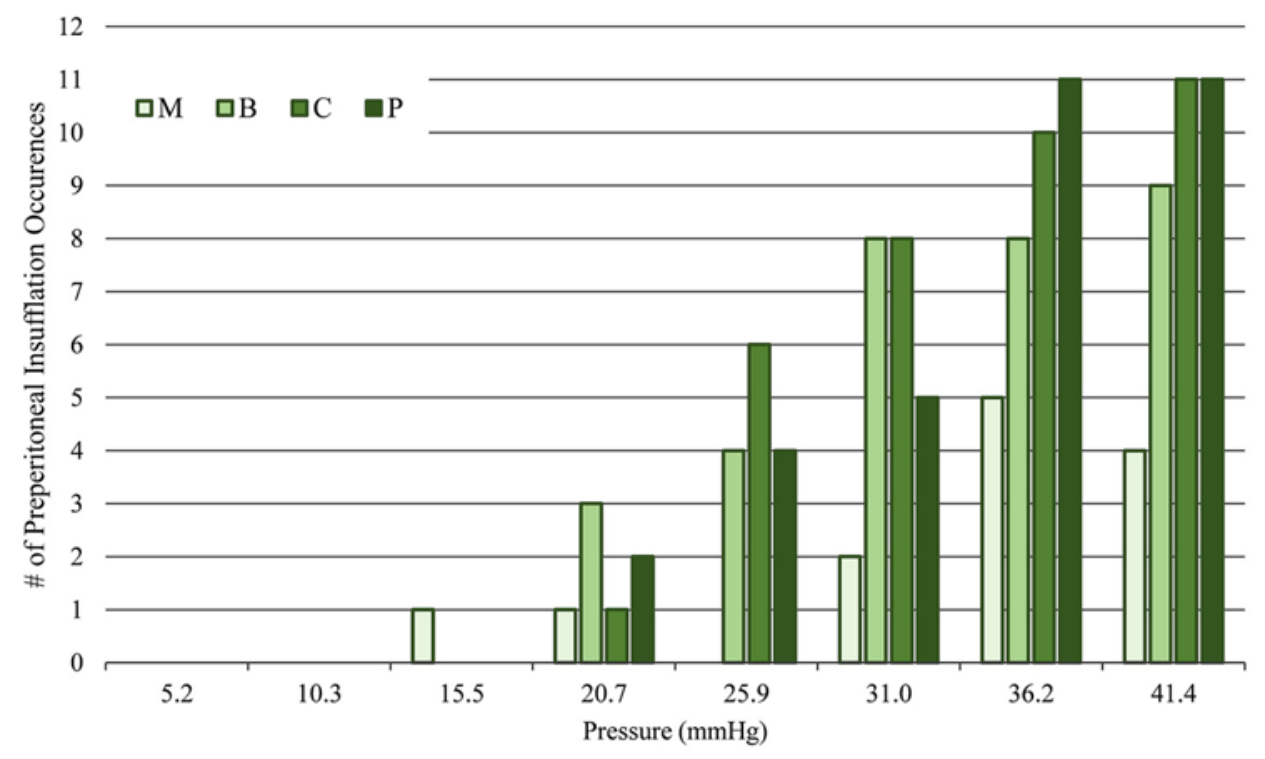

Fig. 4 As the insufflation pressure increases, the likelihood of preperitoneal insufflation also increases. The histogram depicts the number of instances where preperitoneal insufflation occurred in each test category and at each insufflation pressure. All test categories had preperitoneal insufflation pressures at or above $20.7 \mathrm{mmHg}$, except category $\mathrm{M}$ which had two irregularities at 15.5 and $20.7 \mathrm{mmHg}$.

(Fig. 5). During the study, some carcasses did not have a preperitoneal insufflation between 5.2 and $41.4 \mathrm{mmHg}$ for certain test categories. For these categories, pressure tests continued at intervals of $5.2 \mathrm{mmHg}$ until the first instance of preperitoneal insufflation occurred. The locations for the additional tests were cranial to the most superior test category location. One-way ANOVA was used to compare the mean confidence intervals for the test categories, which showed there was a significant difference between mean initial peritoneal cavity insufflation pressure, and each of the means of the lowest preperitoneal insufflation pressures $(p<0.05)$. Also, for our sample size, there was no statistical difference in the minimum insufflation pressure between the two weight groups $(\sim 50 \mathrm{~kg}$ and $\sim 75 \mathrm{~kg})(p>0.05)$. Category X had an initial insufflation pressure of $P_{X}=8.83 \pm 4.19 \mathrm{mmHg}$ (mean $\pm \mathrm{SD}$ ). The average lowest preperitoneal insufflation pressures for categories M, P, C, and B were $P_{M}=$ $40.08 \pm 7.68 \mathrm{mmHg}, P_{P}=31.89 \pm 6.91 \mathrm{mmHg}, P_{C}=29.31 \pm 5.55 \mathrm{mmHg}$, and $P_{B}=28.87 \pm 6.02 \mathrm{mmHg}$, respectively. 


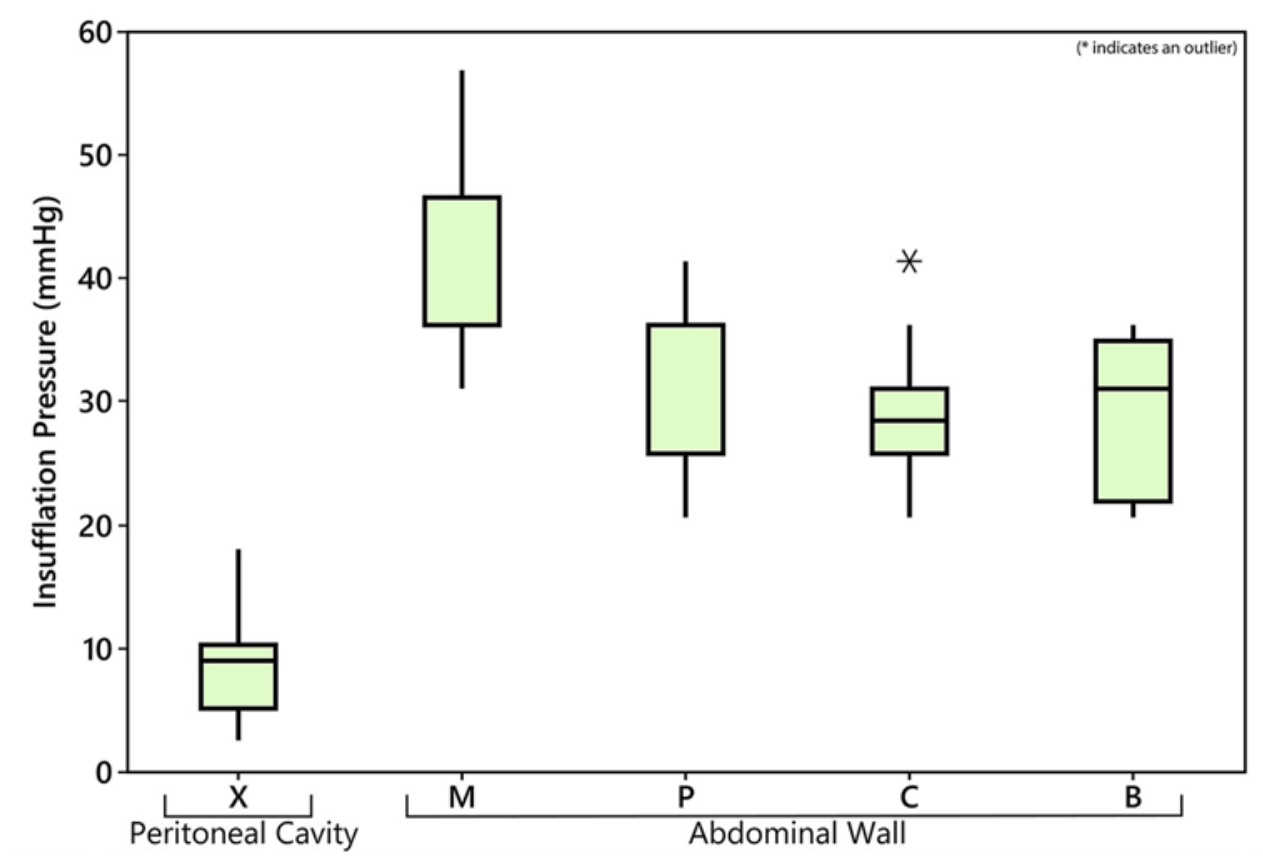

Fig. 5 There exists a pressure threshold that initially insufflates the peritoneal cavity and does not cause abdominal wall (preperitoneal) insufflation. The distribution of the lowest pressures to initially insufflate the peritoneal cavity $(X)$ and the lowest pressures to cause preperitoneal insufflation at each test category ( $M, P, C$, B) for each pig are shown. There was a statistically significant difference $(p<0.05)$ between the mean initial peritoneal cavity insufflation pressure $\left(P_{X}=8.83 \pm 4.19\right.$ $\mathrm{mmHg}$ ) and each of the means of the lowest preperitoneal insufflation pressures $\left(P_{M}=40.08 \pm 7.68 \mathrm{mmHg}, P_{P}=31.89 \pm 6.91 \mathrm{mmHg}, P_{C}=29.31 \pm 5.55 \mathrm{mmHg}, P_{B}\right.$ $=28.87 \pm 6.02 \mathrm{mmHg})($ mean $\pm \mathrm{SD})$.

\section{Discussion}

In this study, an acceptable range of insufflation pressures was determined at four different locations on the abdominal wall as well as the initial peritoneal cavity insufflation pressure in human-sized porcine carcasses. Our results suggest that Veress needle pressures greater than 20 $\mathrm{mmHg}$ at categories $\mathrm{P}, \mathrm{C}$, and $\mathrm{B}$ and $30 \mathrm{mmHg}$ at category $\mathrm{M}$ are likely to cause preperitoneal insufflation. On the other hand, pressures of 8.83 $\pm 4.19 \mathrm{mmHg}$ (mean $\pm \mathrm{SD}$ ) will initially insufflate the peritoneal space. For both subsequent and concomitant insufflation, the target insufflation pressure should be set to a pressure lower than the determined $20 \mathrm{mmHg}$ to avoid preperitoneal insufflation. To compare our porcine 
results to humans, Vilos et al. determined the initial peritoneal cavity insufflation pressure in 256 female humans to be $4.09 \pm 1.34 \mathrm{mmHg}$ (mean \pm SD) [16]. However, there have not been any studies to determine the minimum preperitoneal insufflation pressure within humans. An experiment on fresh cadavers modeled after this study could be used to find such values.

To avoid instances of preperitoneal insufflation while using the technique of subsequent insufflation, the initial insufflation pressure should be within the optimal range $\left(P_{o p t}\right)$. This way the pressure is low enough that if the needle was incorrectly placed within the abdominal wall, it would not insufflate. After correct placement is confirmed by carbon dioxide flowing at the lower pressure, the insufflator setting can be increased to the desired pneumoperitoneum pressure. For concomitant insufflation, as the needle is passed through the abdominal wall layers, the initial insufflation pressure should be within the optimal range $\left(P_{\text {opt }}\right)$. Correct placement can then be confirmed as carbon dioxide flow begins after breaching the parietal peritoneum. After successfully locating the cavity, the insufflation pressure can be increased to the desired pneumoperitoneum pressure.

During one carcass experiment, the initial Veress needle was over inserted into the bowel without any indication. The initial insufflation pressure reading was $7.8 \mathrm{mmHg}$. Thinking the needle was in the potential space of the peritoneal cavity, the experiment continued, and the Veress needle was connected to the insufflator. However, once insufflation began, the cavity did not insufflate evenly as observed when the insufflating needle is placed correctly. This particular test was abandoned, and the carcass abdomen was cut open for inspection. After investigation, the needle had entered and insufflated the large intestine. This adverse event illustrates the need for more research on initial peritoneal cavity access. This study was designed to determine the pressure range suitable to avoid preperitoneal insufflation during Veress needle insertion; however, more research is needed to further address and mitigate the risk of visceral injury.

While the Veress needle is the most common means for establishing pneumoperitoneum, some surgeons prefer the direct trocar method where the primary trocar is placed without pneumoperitoneum [24]. The results from this study can likely be applied to more devices than just the Veress needle by ensuring the initial insufflation 
pressure (or concomitant insufflation pressure) is within the optimal range $\left(P_{o p t}\right)$. However, further testing should be conducted to prove this hypothesis.

A limitation of this study was that the initial peritoneal cavity insufflation pressure was only measured below the umbilicus. Although this is the most common location for placement of the Veress needle [24], future work should be done to show that Palmer's point and the Lee-Huang point also have lower initial insufflation pressures $\left(P_{p c}\right)$ than their respective preperitoneal insufflation pressures $\left(P_{p p i}\right)$. Moreover, the peritoneal cavity was insufflated throughout the study to maintain pneumoperitoneum. This may have increased the abdominal wall resistance and altered the results. Additionally, the study's objective was whether a certain air pressure resulted in preperitoneal insufflation within any layer of the abdominal wall. It may also be useful to classify the pressure to insufflate each of the individual abdominal wall layers. In particular, it was observed that the lowest pressure to result in preperitoneal insufflation usually occurred directly superficial to the parietal peritoneum. Further testing should be done to characterize this section of the abdominal wall as it may be the most likely location for preperitoneal insufflation. Also, omental emphysema and visceral insufflation are issues, and further testing should be done to classify the insufflation pressure of the omentum, mesentery, and the various abdominal organs to determine if pressure profiling is also capable of detecting over puncture of the Veress needle [12].

\section{Conclusion}

We determined, in human-sized porcine models, the initial peritoneal cavity insufflation pressure below the umbilicus, and the preperitoneal insufflation pressure at four different anatomical categories. The results obtained in this study are not a guideline for trocar or Veress needle placement, but rather preliminary data which may lead to more studies, technology, etc. Veress needle pressures greater than $10 \mathrm{mmHg}$ resulted in initial cavity insufflation $\left(P_{p c}\right)$ and pressures greater than 20 $\mathrm{mmHg}$ resulted in preperitoneal insufflation $\left(P_{p p i}\right)$. 
Acknowledgments The project was funded by the Department of Defense-Offutt Air Force Base-STRATCOM award number FA460018D9001;FU911. The animal handling and surgical work were supported by the Institutional Animal Care staff, veterinarians, and technicians from the University of Nebraska-Lincoln.

Disclosures Riley Reynolds, Benjamin Wankum, Sean Crimmins, Mark Carlson, and Benjamin Terry have no conflicts of interest or financial ties to disclose. The views expressed are solely those of the authors and do not reflect the official policy or position of the US Army, US Navy, US Air Force, the Department of Defense, or the US Government.

\section{References}

1. Sakamoto A, Kikuchi I, Shimanuki H, Tejima K, Saito J, Sakai K, Kumakiri J, Kitade M, Takeda S (2017) Initial closed trocar entry for laparoscopic surgery: technique, umbilical cosmesis, and patient satisfaction. Gynecol Minim Invasive Ther 6:167172. https://doi.org/10.1016/i.gmit.2017.04.001

2. Molloy D, Kaloo PD, Cooper M, Nguyen TV (2002) Laparoscopic entry: a literature review and analysis of techniques and complications of primary port entry. Aust N Z J Obstet Gynaecol 42:246-254. https://doi. org/10.1111/j.0004-8666.2002.00246.x

3. Vilos GA, Ternamian A, Dempster J, Laberge PY, Vilos G, Lefebvre G, Allaire C, Arneja J, Birch C, Dempsey T, Dempster J, Laberge PY, Leduc D, Turnbull V, Potestio F (2007) Laparoscopic entry: a review of techniques, technologies, and complications. J Obstet Gynaecol Can 29:433-447. https://doi.org/10.1016/ $\underline{\text { S1701-2163(16)35496-2 }}$

4. Pickett SD, Rodewald KJ, Billow MR, Giannios NM, Hurd WW (2010) Avoiding major vessel injury during laparoscopic instrument insertion. Obstet Gynecol Clin North Am 37:387-397. https://doi.org/10.1016/j.ogc.2010.05.002

5. van der Voort M, Heijnsdijk EAM, Gouma DJ (2004) Bowel injury as a complication of laparoscopy. BJS (Brit J Surg) 91:1253-1258. https://doi.org/10.1002/ bjs. 4716

6. Teng H-C, Yeh H-M, Wang S-M, Ji N (2017) Massive carbon dioxide embolism during pneumoperitoneum for laparoscopic adrenalectomy: a case report. Gen Int Med Clin Innov 1:1000134

7. Antoniou SA, Pointner R, Granderath FA (2011) Single-incision laparoscopic cholecystectomy: a systematic review. Surg Endosc 25:367-377. https://doi. org/10.1007/s0046 4-010-1217-5

8. Frantzides CT, Carlson MA (2008) Atlas of minimally invasive surgery, 1st edn. Saunders, Philadelphia

9. Toro A, Mannino M, Cappello G, Di Stefano A, Di Carlo I (2012) Comparison of two entry methods for laparoscopic port entry: technical point of view. Diagn Ther Endosc. https://doi.org/10.1155/2012/305428 
10. Alkatout I, Mettler L, Maass N, Noé G-K, Elessawy M (2015) Abdominal anatomy in the context of port placement and trocars. J Turk Ger Gynecol Assoc 16:241251. https://doi.org/10.5152/jtgga.2015.0148

11. Yoong W, Saxena S, Mittal M, Stavroulis A, Ogbodo E, Damodaram M (2010) The pressure profile test is more sensitive and specific than Palmer's test in predicting correct placement of the Veress needle. Eur J Obstetr Gynecol Reprod Biol 152:210-213. https://doi.org/10.1016/j.ejogr b.2010.06.007

12. Teoh B, Sen R, Abbott J (2005) An evaluation of four tests used to ascertain Veres needle placement at closed laparoscopy. J Minim Invasive Gynecol 12:153-158. https://doi.org/10.1016/i.jmig.2005.01.011

13. Brill AI (2003) Fundamentals of peritoneal access. J Am Assoc Gynecol Laparosc $10: 11$

14. Mikhail E, Tamhane N, Sarkar P, Sappenfield E, Tanner JP, Imudia AN (2019) Laparoscopic entry technique using a veress needle insertion with and without concomitant $\mathrm{CO}_{2}$ insufflation: a randomized controlled trial. J Minim Invasive Gynecol 26:1383-1388. https://doi.org/10.1016/i.jmig.2019.02.011

15. Ott DE (2019) Abdominal compliance and laparoscopy: a review. JSLS. https:// doi.org/10.4293/ISLS.2018.00080

16. Vilos GA, Vilos AG (2003) Safe laparoscopic entry guided by veress needle CO2 insufflation pressure. J Am Assoc Gynecol Laparosc 10:415-420. https://doi. org/10.1016/S1074-3804(05)60277-0

17. Wong SSC, Irwin MG (2018) Anaesthesia and minimally invasive surgery. Anaesth Intensive Care Med 19:11-15. https://doi.org/10.1016/j. mpaic.2017.10.005

18. National Research Council (US) Committee for the Update of the Guide for the Care and Use of Laboratory Animals (2011) Guide for the care and use of laboratory animals, 8th edn. National Academies Press (US), Washington (DC)

19. Home. In: AAALAC. https://www.aaalac.org/ Accessed 5 May 2020

20. Home | OLAW. https://olaw.nih.gov/ Accessed 5 May 2020

21. Plymouth Ag Group-Feeding the world, one pig at a time. In: Plymouth Ag Group. https://pagpork.farm/ Accessed 5 May 2020

22. Glass KB, Tarnay CM, Munro MG (2002) Intraabdominal pressure and incision parameters associated with a pyramidal laparoscopic trocar-cannula system and the EndoTIP Cannula. J Am Assoc Gynecol Laparosc 9:508-513. https://doi. org/10.1016/S1074-3804(05)60528-2

23. Steffey MA (2016) Laparoscopic-assisted surgical procedures. Vet Clin N Am 46:45-61. https://doi.org/10.1016/j.cvsm.2015.07.002

24. Thepsuwan J, Huang K-G, Wilamarta M, Adlan A-S, Manvelyan V, Lee C-L (2013) Principles of safe abdominal entry in laparoscopic gynecologic surgery. Gynecol Minim Invasive Ther 2:105-109. https://doi.org/10.1016/i.gmit.2013.07.003

25. Huang K-G, Lee C-L (2013) Lee-Huang point 20 years on. Gynecol Minim Invasive Ther 2:103-104. https://doi.org/10.1016/i.gmit.2013.08.001 
26. Javed A, Shashikiran BD, Aravinda PS, Agarwal AK (2020) Laparoscopic versus open surgery for the management of postcholecystectomy benign biliary strictures. Surg Endosc. https://doi.org/10.1007/s0046 4-020-07496-6

27. Morton J, Hardwick RH, Tilney HS, Gudgeon AM, Jah A, Stevens L, Marecik S, Slack M (2020) Preclinical evaluation of the versius surgical system, a new robot-assisted surgical device for use in minimal access general and colorectal procedures. Surg Endosc. https://doi.org/10.1007/s0046 4-020-07622-4 